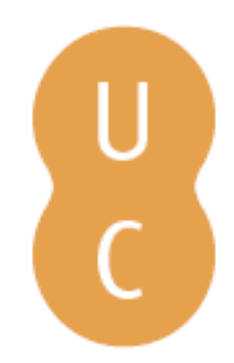

\title{
pommalina
}

\section{Fast computational models of dynamic fire propagation using near-field techniques}

\author{
Autor(es): $\quad$ Hilton, J. E.; Sharples, J. J.; Sullivan, A. L.; Swedosh, W.
}

Publicado por: Imprensa da Universidade de Coimbra

URL

persistente: URI:http://hdl.handle.net/10316.2/44628

DOI: $\quad$ DOI:https://doi.org/10.14195/978-989-26-16-506_111

Accessed : $\quad$ 26-Apr-2023 12:02:24

A navegação consulta e descarregamento dos títulos inseridos nas Bibliotecas Digitais UC Digitalis, UC Pombalina e UC Impactum, pressupõem a aceitação plena e sem reservas dos Termos e Condições de Uso destas Bibliotecas Digitais, disponíveis em https://digitalis.uc.pt/pt-pt/termos.

Conforme exposto nos referidos Termos e Condições de Uso, o descarregamento de títulos de acesso restrito requer uma licença válida de autorização devendo o utilizador aceder ao(s) documento(s) a partir de um endereço de IP da instituição detentora da supramencionada licença.

Ao utilizador é apenas permitido o descarregamento para uso pessoal, pelo que o emprego do(s) título(s) descarregado(s) para outro fim, designadamente comercial, carece de autorização do respetivo autor ou editor da obra.

Na medida em que todas as obras da UC Digitalis se encontram protegidas pelo Código do Direito de Autor e Direitos Conexos e demais legislação aplicável, toda a cópia, parcial ou total, deste documento, nos casos em que é legalmente admitida, deverá conter ou fazer-se acompanhar por este aviso. 


\section{ADVANCES IN}

\section{FOREST FIRE RESEARCH}

\section{8}

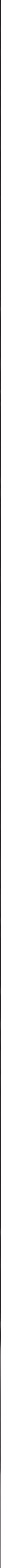




\title{
Fast computational models of dynamic fire propagation using near-field techniques
}

\author{
J. E. Hilton ${ }^{1 *}$; J. J. Sharples ${ }^{2}$; A. L. Sullivan ${ }^{3}$; W. Swedosh ${ }^{1}$ \\ ${ }^{1}$ CSIRO, Clayton, VIC 3168, Australia, \{james.hilton@csiro.au*\} \\ ${ }^{2}$ UNSW, Canberra, ACT 2610, Australia \\ ${ }^{3}$ CSIRO, Canberra, ACT 2601, Australia
}

\begin{abstract}
Modelling of wildfires is required for risk assessment and predicting the behavior of a potential or ongoing wildfire. Computational physics-based models can calculate the full combustion dynamics of a wildfire, but these are currently too computationally costly to be used for rapid operational predictions. As a result, many operational prediction systems for wildfires are based on rapid two-dimensional propagation algorithms which model only the outward growth of the fire perimeter. These take a fraction of the calculation time of physics-based models as factors such as the rate-of-spread of the fire are generally implemented using empirical expressions. The predictive ability of these perimeter propagation models is, however, governed by the limitations of the algorithm used. We introduce a two-dimensional perimeter propagation model that incorporates aspects of a full three-dimensional physics-based model using near-field approximations to fireinduced air flows. The model comprises a two-dimensional perimeter propagation approach with an additional near-field physics-based component allowing more complex fire behavior to be predicted rapidly enough for operational usage. We show examples of various aspects of fire behavior which can be modelled using a near-field approach that were previously difficult, or impossible, to simulate in two-dimensional perimeter propagation approaches. These include fire line interaction, wind and terrain effects, fire shape development and vortex sources. The method allows all of these aspects to be incorporated in perimeter propagation using a single computational approach. Comparison to experimental results are provided, showing an excellent fit between the model and experimental fires. The near-field approach may improve the accuracy of rapid computational models with low additional overhead, suitable for operation usage.
\end{abstract}

Keywords: Wildfire modelling, wildfire behaviour

\section{Introduction}

Computer modelling of wildfire behaviour ranges from risk management and operational predictions of a potential or actual wildfire in progress, to physics-based models investigating the complex processes and dynamics of wildfires. Currently, many operational prediction systems use rapid two-dimensional perimeter propagation models, which are based on empirical rate-of-spread models for specific fuel types. Perimeter propagation models use a range of different computational algorithms such as cellular automata, front-tracking techniques and level set methods (Sullivan 2009a). Generally, these methods track or model the fire perimeter and advance the perimeter based on local fuel, weather and topographic information to provide a prediction of the wildfire's extent at future times. Although very fast (taking on the order of seconds to minutes to complete a prediction of several simulated hours) they are limited by the analytical nature of the perimeter propagation algorithm. In contrast, three-dimensional physics-based wildfire models can model the entire combustion and air flow dynamics around a wildfire to a high degree of accuracy as they are based on discretisation and solution of the fluid and thermo-dynamic equations (Sullivan 2009b). Currently, however, these models are too computationally costly to be used in operational predictions, taking on the order of hours to days for a simulation to complete on a supercomputer. 


\section{Near-field techniques}

We have developed a two-dimensional perimeter propagation model that incorporates aspects of a full three-dimensional physics-based model using near-field approximations to fire-induced flows. The model is fully detailed and compared to a number of experimental results in Hilton et al. (2018). Specifically, the model comprises a two-dimensional perimeter propagation approach with an additional physics-based component allowing new types of fire behaviour to be predicted rapidly enough for operational usage. The additional component is a near-field approximation to the groundlevel fire-induced flow $\mathbf{u}$, which is represented using a Helmholtz decomposition in terms of a local scalar potential, $\psi$, and a vector potential, $\chi$.

$$
\mathbf{u}=\nabla \psi+\nabla \times \chi
$$

The scalar 'pyrogenic' potential is, essentially, the ground-level pressure field in the presence of any fires and the vector potential arises from any large-scale sources of vorticity present around the fire.

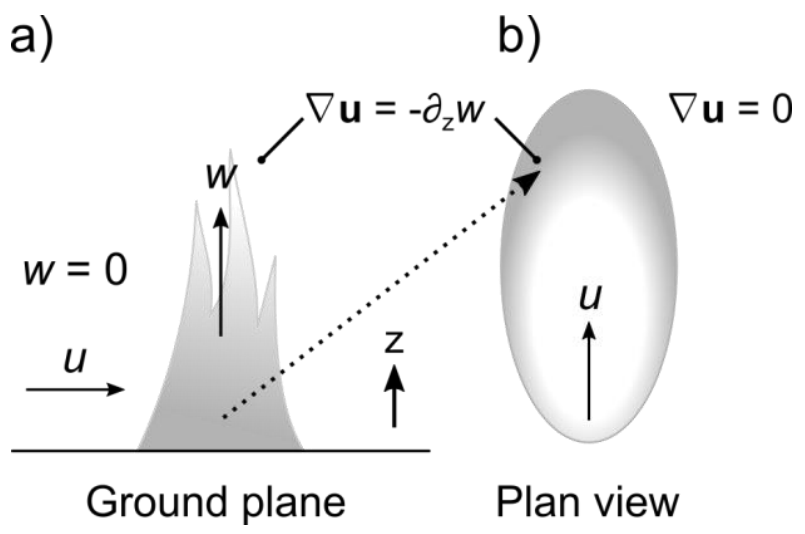

Figure 1 - Schematic overview of near-field model, a) flaming region on ground plane and b) fire perimeter from above. The forcing in Eq. (2) is assumed to be non-zero only within the flaming regions.

The near-field model requires two extra computational steps in addition to a standard perimeter propagation model. The first is the calculation of the source terms for the near-field and the second is the calculation of the field itself requiring the solution of a two-dimensional Poisson equation for the scalar potential and a solution of set of two-dimensional Poisson equations for the vector potential:

$$
\nabla^{2} \psi=-\partial_{z} w \quad \nabla^{2} \boldsymbol{\chi}=\boldsymbol{\omega}
$$

where $w$ is the vertical air flow and $\omega$ is a specified vorticity. Once the set of Poisson equations, Eq. (2), are solved, the local wind field due to near-field effects can be calculated using Eq. (1) and added to the global (ambient) wind field. In this work, all simulations were carried out in the Spark framework (Miller et al., 2015), a level set based perimeter propagation solver. The Poisson equations, Eq. (2), were solved using a multigrid technique. Although the near-field model has been implemented here using a level set solver, the process could be applied to other perimeter propagation methods such as front tracking or cellular automata methods. A related method using cellular automata has previously been developed (Sullivan and Knight, 2004), which used the geometric centre of all burning cells to model a central convective column to provide an additional in-drawn component of wind. This previous model replicated the key effects of the model presented here using a semi-physical approach in which the forcing was essentially reduced to a single point at the centre of the fire.

From investigation and comparison to experimental fires the vector potential appears to be negligible in most cases, although may be important in certain situations where wind interacts with topography to form lateral vortices (Simpson et al., 2013). A key component of the scalar potential is the upward forcing of air within flaming regions of the fire. A schematic overview of this forcing is 
shown in Figure. The model uses the simple approximation of the vertical wind component, $w$, being zero outside the fire and non-zero within any flaming regions. Similarly, the vertical gradient of this component, $-\partial_{\mathrm{z}} w$, required for Eq. (2) is similarly assumed to be non-zero only within the flaming regions.
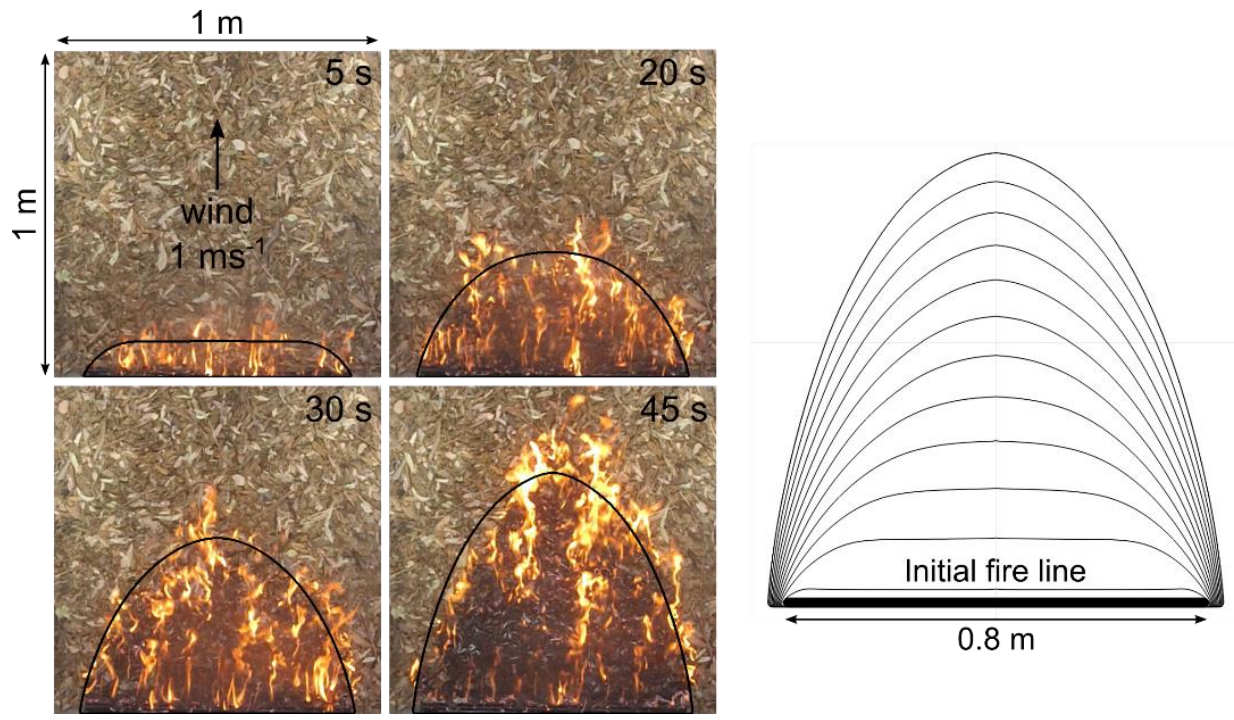

Figure 2 - Comparison of near-field model to experimental results (left) and simulation isochrones showing parabolic rounding arising naturally from the model (right).

The exact form and relationship between this vertical component and the parameters of the fire are currently being investigated and compared to experiments, the aim of which will be to characterise this vertical gradient for real-world conditions. However, the forcing will clearly be dependent of some function of heat release or flame temperature driving buoyant convection. Heat release can be modelled using a combustion curve of the form:

$$
I(t)=\frac{H M_{0}}{\tau} e^{-\frac{t}{\tau}}
$$

where $I$ is the heat intensity $\left(\mathrm{W} \mathrm{m}{ }^{-2}\right)$ at time $t(\mathrm{~s}), H$ is the heat of combustion $\left(\mathrm{J} \mathrm{kg}^{-1}\right), M_{0}$ is the initial fuel load $\left(\mathrm{kg} \mathrm{m}^{-2}\right)$ and $\tau$ is the mean lifetime of the burning fuel. Results using Eq. (3) have shown a close match to experimental ring fires simulated using fully physical models (Thomas, 2018). However, a simple forcing of the form $I \propto s$, where $s$ is the local speed of the fire, has been found to give surprisingly good results in comparison to small and medium-scale experiments. Simulations using this simple forcing are shown in Figure, with $-\partial_{\mathrm{z}} w=k s$ and the rate-of-spread in the normal direction $\mathbf{n}$ is a 'first-order' model (Hilton et al. 2016) given by:

$$
s=u_{0}+u_{1} \max (\hat{\mathbf{u}} \cdot \hat{\mathbf{n}}, \mathbf{0})
$$

with $\mathrm{u}_{0}=0.5 \mathrm{~mm} \mathrm{~s}^{-1}, \mathrm{u}_{1}=0.04$ and $k=80$, where these values were manually matched to the experimental data. The predicted fire perimeter is shown as a black line superimposed over images of experiments performed in the CSIRO Pyrotron (Sullivan et al., 2013).

The near-field model has also been shown to match results from larger grass fire experiments on open plots of 33 meters per side (Hilton et al., 2018). We are currently investigating whether the model is applicable to larger or more intense wildfires as the experimental data sets used so far cover only a limited range of the possible parameter space for fires and, of course, cannot model complex transitions in fire behaviour such as flame attachment (Apte et al., 1991, Tang et al., 2017). Despite this, the model appears to provide a close match to the experimental fires under the range of parameters considered and has the potential to include more complex modes of fire behaviour at low cost. 


\section{Inclusion of additional fire behaviour effects}

The use of near-field techniques permits modelling of aspects of fire behaviour that were previously difficult, or impossible, to simulate in two-dimensional perimeter propagation approaches. This includes the attraction between nearby fires, an example of which is shown in Figure for two fires lit in close proximity to each other. The results on the left show isochrones from a standard simulation, and the results on the right show the isochrones using the near-field model. For comparison these simulations use the same rate-of-spread model given in Eq. (4). However, the attractive behaviour is independent of the underlying rate-of-spread model used as it is a consequence of coupling though the near-field interaction.

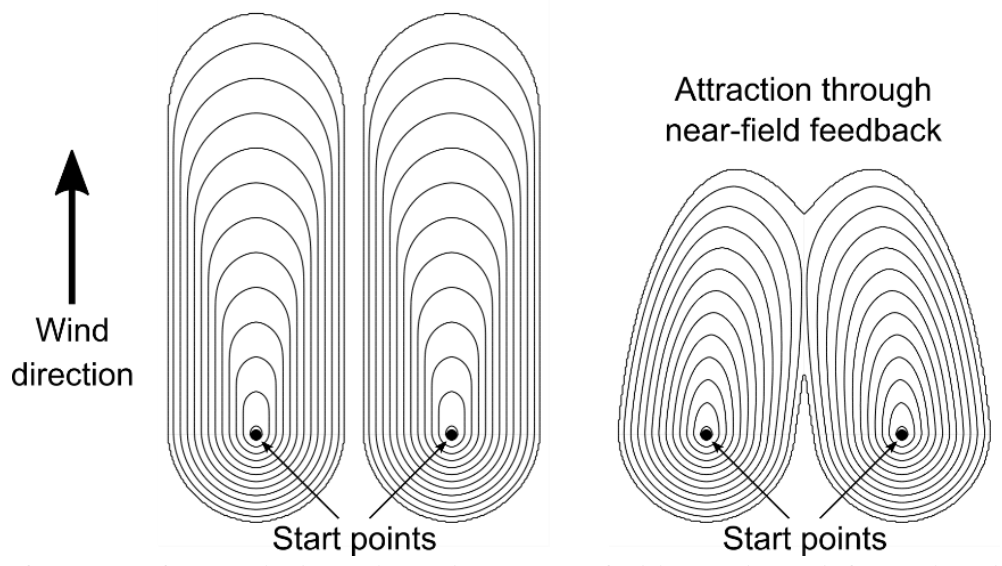

Figure 3 - Isochrones from two fires side-by-side without near-field coupling (left) and with coupling (right). The near-field coupling predicts the fires attract, a phenomenon observed in experiments.

This attraction has been observed in experimental ' $\mathrm{V}$ '-line or junction fires (Sullivan et al., in preparation) and may play a major role in fires ignited by ember storms as the coalescence rate of multiple small spot fires is significantly higher when this attractive effect is taken into account (Hilton et al., 2018).

A second behaviour is the parabolic rounding exhibited by a wind-driven fire line, as shown in Figure for a fire line lit in uniform wind conditions. The parabolic rounding arises naturally when using the near-field approach and is not required to be added as an additional phenomenological component to a two-dimensional rate-of-spread model. The close match to observed fires also suggests that a pressure, rather than radiative, effect may be responsive for such parabolic shapes, at least for the limited set of fire conditions investigated for this and previous studies.
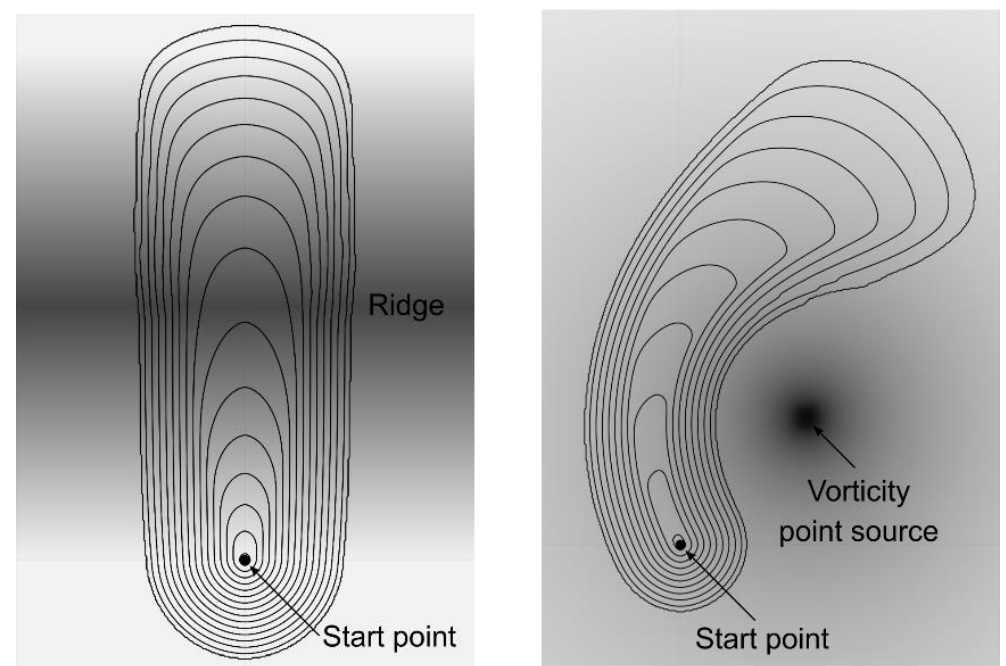

Figure 4 - Incorporation of terrain into the near-field model as a source term for the scalar potential (left). Example of fire propagation in the presence of a vortex point source (right). 
The expression for the source term in Eq. (2), $\partial_{z} w$, is a vertical displacement of air from the fire. This is mathematically identical to a forcing term from lifting of air over terrain which easily be incorporated into the model using the local terrain gradient, an example of which is shown on the left of Figure. The simulated fire in this example is started downwind of a ridge (elevation is shown as shaded grey in the image, with dark grey high elevation) and can be seen to accelerate on the windward slope and decelerate on the lee slope of the ridge, in general agreement with empirical models of fire behaviour on slopes (McArthur, 1967). The applicability of the model to provide a topological correction in this manner is currently under investigation. The use of the near-field model in this manner is, essentially, a single-level approximation to a diagnostic wind field mass correction (Ross et al., 1988) which can be implemented at a substantially reduced computational cost as a threedimensional terrain-following discretisation does not have to be used.

Fully three-dimensional vorticity fields can be applied using the model if required, but for circulation in the ground plane the vector potential reduces to a single component $\omega_{z}$ requiring the solution of only one additional Poisson equation. An example of incorporating circulation in the ground plane is shown on the right of Figure, where a single point source of vorticity has been applied. The resulting isochrones from a fire starting at a point nearby are shown, superimposed over vorticity potential $\chi_{z}$ (shaded by magnitude in greyscale). The simulation isochrones can be seen to follow the circulation, the strength of which is given by the magnitude of the original point source.

Notably, as the near-field model is linear terrain correction and near-field pressure effects from buoyant convection can simply be added in the model and require no additional computational effort as only one scalar Poisson equation needs to be solved.

\section{Conclusions}

The near-field modelling technique presented here potentially allows fire line interaction, wind and terrain effects, fire shape development and vortex sources to be incorporated in perimeter propagation using a unified computational approach. Development of the model is currently ongoing with research into an appropriate and representative forcing for large-scale wildfires. This near-field approach may improve the accuracy of rapid computational models with low additional overhead suitable for operation usage.

\section{References}

Apte V, Bilger R, Green A, Quintiere J (1991) Wind-aided turbulent flame spread and burning over large-scale horizontal PMMA surfaces. Combustion and Flame 85, 169-184.

Hilton JE, Sullivan AL, Swedosh W, Sharples JJ, Thomas C (2018) Incorporating convective feedback in wildfire simulations using pyrogenic potential, Environmental Modelling \& Software, 107, 12 24.

Hilton JE, Sharples JJ, Sullivan AL, Swedosh W (2017) Simulation of spot fire coalescence with dynamic feedback, In Syme, G., Hatton MacDonald, D., Fulton, B. and Piantadosi, J. (eds) MODSIM2017, 22nd International Congress on Modelling and Simulation. Modelling and Simulation Society of Australia and New Zealand, 1111-1117.

JE Hilton, C Miller, AL Sullivan (2016) A power series formulation for two-dimensional wildfire shapes, International Journal of Wildland Fire, 25, 970-979.

McArthur AG (1967) Fire behaviour in eucalypt forest. Commonwealth of Australia Forestry and Timber Bureau, Canberra, ACT. Leaflet No. 107.

Miller C, Hilton JE, Sullivan AL, Prakash M (2015) Spark - A Bushfire Spread Prediction Tool. In: Denzer R., Argent R.M., Schimak G., Hřebíček J. (eds) Environmental Software Systems. 
Infrastructures, Services and Applications. ISESS 2015. IFIP Advances in Information and Communication Technology, 448. Springer, Cham.

Ross DG, Smith IN, Manins PC, Fox DG (1988) Diagnostic wind field modeling for complex terrain: model development and testing, Journal of Applied Meteorology, 27, 785-796.

Simpson CC, Sharples JJ, Evans JP, McCabe MF, (2013) Large eddy simulation of atypical wildland fire spread on leeward slopes. International Journal of Wildland Fire, 22 599-614.

Sullivan AL, Knight IK (2004) A hybrid cellular automata/semi-physical model of fire growth. AsiaPacific Conference on Complex Systems, Complex 09, Cairns, Australia.

Sullivan AL (2009a) Wildland surface fire spread modelling, 1990-2007. 3: Simulation and mathematical analogue models. International Journal of Wildland Fire, 18, 387-403.

Sullivan AL (2009b) Wildland surface fire spread modelling, 1990-2007. 1: Physical and quasiphysical models. International Journal of Wildland Fire, 18, 349-368.

Sullivan AL, Knight IK, Hurley R, Webber C (2013) A contractionless, low-turbulence wind tunnel for the study of free-burning fires. Experimental Thermal and Fluid Science 44, 264-274.

Sullivan AL, Swedosh W, Hurley R, Sharples JJ, Hilton J E, (In Preparation) Investigation of the effects of interactions of intersecting oblique fire lines, with and without wind.

Tang W, Miller CH, Gollner MJ, (2017) Local flame attachment and heat fluxes in wind-driven line fires. Proceedings of the Combustion Institute 36, 3253-3261.

Thomas C.M., Sharples J.J., Hilton J., Evans JP, (2018) Rate of spread in coupled models: fireline curvature and pyrogenic potential, In D. X. Viegas (Ed.), Advances in Forest Fire Research. 